\title{
ENTREVISTA
}

\section{BASE NACIONAL COMUM CURRICULAR - DEBATES E MOVIMENTOS}

\footnotetext{
A Base Nacional Comum Curricular (BNCC), que inclusive Avem sendo tema de uma série de audiências públicas abertas à sociedade, promovidas pelo Conselho Nacional de Educação (CNE), visa consolidar um conjunto de orientações para a composição das competências essenciais que deverão constar no currículo de todas as escolas de Educação Básica do Brasil. Nesta entrevista exclusiva para o Boletim Técnico do Senac, uma das líderes do movimento Todos pela Educação, que monitora e promove projetos norteadores para o futuro da educação brasileira, fala sobre a participação do Movimento para o avanço da BNCC.
} 


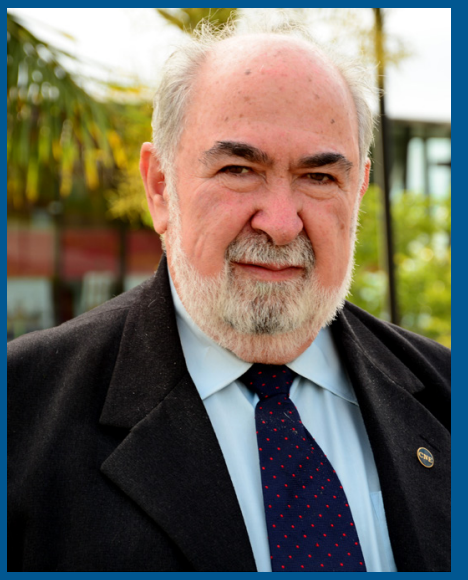

\section{Professor Francisco Aparecido Cordão}

Especialista em Educação Profissional. Titular da

Cadeira 28 da Academia

Paulista de Educação. Peabiru Educacional. São Paulo, São Paulo, Brasil.

facordao@uol.com.br

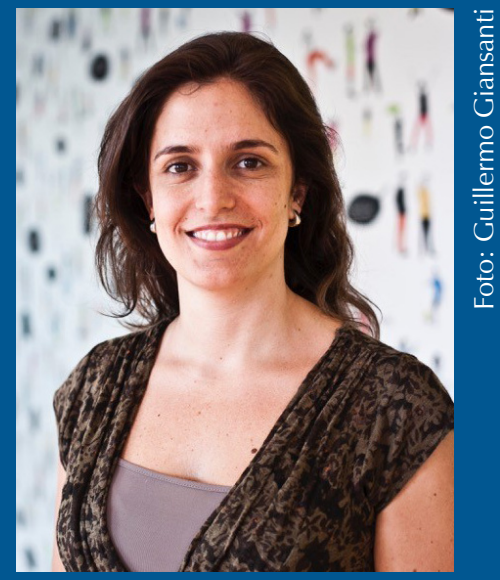

\section{Alice Ribeiro}

Sócia-efetiva do Movimento Todos pela Educação. Rio de Janeiro, Rio de Janeiro, Brasil.

basenacionalcomum@gmail. com 
Francisco Aparecido Cordão - Na qualidade de Conselheiro da Câmara de Educação Básica (CEB) do Conselho Nacional de Educação (CNE), eu tive a honra de participar desde o início, praticamente como um dos fundadores, de dois importantes movimentos que eu identifico como sendo da sociedade civil educacional organizada: O Movimento Todos pela Educação e o Movimento de Apoio pela Base Nacional Comum Curricular (BNCC). Eu julgo que esses dois movimentos guardam uma articulação quase umbilical em relação às chamadas "Aprendizagens Essenciais que todos os alunos devem desenvolver ao longo das etapas e modalidades da Educação Básica", conforme preconizado pelo MEC, que o Movimento Todos pela Educação já identificou como "Direitos de Aprendizagem", em importante seminário internacional realizado no Plenário do CNE. É isso mesmo? Como um movimento se articula com o outro e ambos impulsionam o desenvolvimento da educação nacional, em termos de uma educação democrática de qualidade?

Alice Ribeiro - O Movimento Todos Pela Educação e o Movimento pela Base Nacional Comum compartilham de valores, objetivos, e atuam de maneira coordenada e próxima, com o intuito de impulsionar o desenvolvimento da educação nacional. O Todos Pela Educação, por um lado, realiza importante atuação de monitoramento e promoção da universalização do acesso de todas as crianças e adolescentes à escola, alfabetização na idade certa, aprendizagem de qualidade para todos, conclusão dos ciclos nas idades corretas e financiamento ampliado e bem-gerido. Além disso, realiza ações voltadas a questões fundamentais para a melhoria da educação, como a valorização dos professores e a mobilização da sociedade.

Já o Movimento pela Base Nacional Comum mergulha no apoio à criação e implementação da Base, um documento que deve explicitar o que é esperado que todo aluno aprenda, ou seja, os direitos de aprendizagem e desenvolvimento de cada criança e adolescente brasileiros. Assim, a Base Nacional deve trazer uma espinha dorsal para o sistema educacional do País, alinhando a esses direitos de aprendizagem e desenvolvimento elementos como a formação dos professores, os materiais didáticos e as avaliações. Dessa maneira, nota-se que a Base Nacional traz contornos e parâmetros mais claros, inclusive para a consecução das metas de qualidade do Todos Pela Educação, pois explicita o que é esperado que os alunos aprendam em cada ano.

O Todos Pela Educação é um dos membros fundadores do Movimento pela Base e tem tido atuação fundamental para colocar o tema na agenda pública do País, assim como para ampliar e aprofundar as discussões sobre o assunto.

Francisco Aparecido Cordão - A questão da "formação básica comum" já estava prevista no art. 210 da Constituição Federal de 1988, foi retomada no art. 26 da LDB de 1996 (Lei n. 9.394/1996) como "base nacional comum" 
e foi incluída na estratégia 2.1 da meta 2 do Plano Nacional de Educação (PNE), aprovado pela Lei n. 13.005/2014 como "proposta de direitos e objetivos de aprendizagem e desenvolvimento". Por que essa demora toda em definir esses "direitos e objetivos" relacionados com as aprendizagens essenciais que todos os alunos devem desenvolver ao longo das etapas e modalidades da Educação Básica? São quase 30 anos contados da Constituição Federal, mais de 20 anos da LDB e quase três anos da Lei do PNE, que havia determinado o máximo de dois anos para tal definição. Essa demora objetiva garantir maior participação?

Alice Ribeiro - A Base Nacional Comum consta há décadas em diversos marcos legais brasileiros e a demora para a sua construção passa por diversos aspectos históricos e conjunturais. Alguns desses aspectos incluem o fato de o País, em um passado recente, ter vivido um período de ditadura, que deixou como herança uma resistência a tudo que pudesse lembrar algum grau de centralização e padronização, ao que se soma a consolidação dos municípios como entes federativos com autonomia curricular, a resistência de grupos que se opunham à construção de um documento com maior grau de especificação, entre outros. Portanto, a demora pouco ou nada teve a ver com a garantia de maior participação no processo de construção da BNCC.

No entanto, isso não quer dizer que o País ficou parado em termos de processos de decisão, construção e implementação curricular. Em nível nacional, foram construídos os Parâmetros Curriculares Nacionais, assim como duas gerações de Diretrizes Curriculares para Todas as Etapas e Modalidades da Educação Básica. Esses documentos trazem nortes importantes, mas, por terem um caráter mais amplo e genérico, na prática permitem muitas diferenças entre o que os sistemas e as escolas oferecem em termos de aprendizagens essenciais. O Congresso já passou, e ainda discute de maneira frequente, propostas de inclusão de conteúdos obrigatórios para a Educação Básica, o que contribui para o inchaço e a fragmentação curriculares. A instauração de um robusto sistema de avaliações de larga escala antes de se estabelecerem com clareza as aprendizagens essenciais para todos os alunos fez com que as avaliações influenciassem os conteúdos dos documentos curriculares - quando o contrário é o que deveria acontecer. Em nível subnacional, pesquisas recentes do Centro de Estudos e Pesquisas em Educação, Cultura e Ação Comunitária (Cenpec) e da Fundação Carlos Chagas apontam que, na última década, verificou-se grande movimento de construção e/ ou renovação curricular nos estados brasileiros.

Este é o cenário mais amplo em que se dá a atual construção da Base Nacional Comum: há bastante movimento, mas também grande variação no que diz respeito a concepção, estruturação, elaboração, conteúdo e implementação dos documentos curriculares existentes pelo País. Essas variantes fazem os alunos terem acesso a aprendizagens muito diferentes, além disso, 
elementos como a formação de professores, as matrizes de avaliação e os materiais didáticos estão desalinhados. É com o intuito de partilhar esses elementos e explicitar claramente quais são esses direitos que a BNCC vem sendo construída. O País vem percorrendo uma longa trajetória em seus processos de decisão, construção e implementação curricular, e a BNCC é um importante passo nessa caminhada.

Francisco Aparecido Cordão - Ainda que tenham sido cinco as versões da BNCC trabalhadas no âmbito do MEC até chegar formalmente no CNE para apreciação formal do colegiado, o que existe de diferença significativa nestas três últimas redações da BNCC? Mais que isso, que relações você identifica entre as três redações da BNCC, os chamados "Parâmetros Curriculares Nacionais", definidos e divulgados pelo MEC, e o conjunto das Diretrizes Curriculares Nacionais produzidas pelo CNE no período de 1988 até 2013 como atos normativos do Colegiado para os Sistemas e Estabelecimentos de Ensino no âmbito da Educação Básica? O diálogo entre a BNCC e as Diretrizes Curriculares Nacionais tem sido bom?

Alice Ribeiro - De maneira geral, pode-se dizer que as diversas versões da Base Nacional Comum apresentaram evoluções importantes em termos de aquisição de maior clareza, objetividade, coerência, foco no aluno e em seu desenvolvimento integral.

A BNCC se aproxima dos Parâmetros e das Diretrizes Curriculares Nacionais à medida que todos buscam trazer nortes para a educação nacional, têm a diversidade cultural como parte integrante e respeitam a autonomia dos sistemas de ensino. Entretanto, a Base se diferencia dos Parâmetros e das Diretrizes Curriculares Nacionais ao trazer uma prescrição bastante objetiva do que é esperado que os alunos aprendam, em uma linguagem direcionada especialmente para escolas e professores, e também por ter sido construída em colaboração com estados e municípios e submetida a amplas consultas públicas. A BNCC também se diferencia dos Parâmetros por ser de natureza obrigatória. Assim, explicita de forma mais clara os direitos de aprendizagem e desenvolvimento de todos os alunos e exige que todos os sistemas de ensino se reorganizem para cumpri-los.

Francisco Aparecido Cordão - É sabido que o Brasil sempre tratou com certo descaso a educação básica de seu povo, embora não faltassem gritos de alerta, tais como o brado lançado pelo deputado Rui Barbosa em seu parecer sobre a Reforma da Instrução Pública, em debate no ano de 1882, que conclamou o parlamento brasileiro a engajar-se em uma verdadeira "cruzada nacional contra a ignorância popular, mãe de todas as servilidades"; o brado lançado pelo Manifesto dos pioneiros da educação nova ao povo e ao governo brasileiro, em 1932, propondo que a reconstrução educacional no Brasil assumisse o papel da grande prioridade nacional, uma vez que, 
"na hierarquia dos problemas nacionais, nenhum sobreleva em importância e gravidade ao da educação". Com todos esses alertas, ainda chegamos à beira das comemorações do nosso bicentenário da Independência, no ano cada vez mais próximo de 2022, sem ter muito o que comemorar em matéria de educação. O que esses movimentos da sociedade civil educacional estão fazendo para ajudar os educadores brasileiros neste esforço de superação da enorme dívida social do Brasil para com seu povo? Entendo que a ninguém é dado se omitir neste momento.

Alice Ribeiro - Avanços relevantes foram alcançados na educação brasileira. Um exemplo claro é o acesso à educação: no século 20, o aumento da taxa de atendimento na fase em que a escolaridade era obrigatória (7-14 anos) foi crescente, e saltou de 49,3\% em 1960 para 96,4\%, em 2000, segundo dados do Instituto Brasileiro de Geografia e Estatística (IBGE) e do Instituto Nacional de Estudos e Pesquisas Educacionais Anísio Teixeira (Inep). O País também conta hoje com um robusto sistema de avaliação, que permite aferir como está a aprendizagem de seus alunos no fim de ciclos relevantes da Educação Básica (ciclo de Alfabetização, Ensino Fundamental 1, Ensino Fundamental 2 e Ensino Médio). Aliás, é esse mesmo sistema de avaliação que aponta que um dos maiores desafios que persistem na educação brasileira é a garantia de qualidade para todos.

Muitos movimentos da sociedade civil organizada têm trabalhado com o intuito de promover acesso, aprendizagem e desenvolvimento adequados ao século 21, o que significa um esforço por conclusão dos ciclos nas idades corretas; ampliação e boa gestão do financiamento; valorização e capacitação dos professores; transparência e divulgação para os principais indicadores educacionais; aproximação entre família, escola e comunidade; apoio aos sistemas de ensino; fomento ao regime de colaboração; disseminação de boas práticas; inclusão; entre muitos outros objetivos. E isso tem se dado por meio das mais diversas estratégias, que têm contribuído para a elaboração e implementação de políticas públicas que promovam qualidade e equidade na educação.

Francisco Aparecido Cordão - Sei que o Movimento pela Base Nacional Comum tem trazido ao Brasil grandes especialistas do mundo todo para debater este tema com os educadores brasileiros. De onde vieram esses especialistas e em que suas experiências e conhecimentos têm ajudado efetivamente o Brasil a melhor definir sua proposta educacional?

Alice Ribeiro - O Movimento pela Base Nacional Comum tem buscado sempre ampliar e aprofundar as discussões em torno da construção e implementação a partir de evidências nacionais e internacionais. Para isso, buscamos uma série de pesquisas, que têm sido amplamente debatidas, por exemplo: para aprender com as experiências que os estados brasileiros têm 
tido na construção e implementação de documentos curriculares de Ensino fundamental acessamos o Cenpec, e para o Ensino médio, a Fundação Carlos Chagas. o Cenpec, aliás, colaborou para a compreensão dos consensos e dissensos acerca da construção de uma base curricular comum. Também vimos como os estados organizam suas cargas horárias acessando pesquisas do Conselho Nacional de Secretários de Educação (Consed) e do Instituto Unibanco; já para estudar o histórico das políticas curriculares da Educação Básica no Brasil, lemos Guiomar Namo de Mello, que também deu apoio à tradução e aos comentários pertinentes à versão brasileira do Glossário de Terminologia Curricular da Organização das Nações Unidas para a Educação, a Ciência e a Cultura (Unesco). No entendimento de como professores e gestores públicos municipais veem a construção de uma base curricular, foram fundamentais, respectivamente, o Instituto Brasileiro de Opinião e Estatística (Ibope) e a União Nacional dos Dirigentes Municipais de Educação (Undime). Por fim, para entendimento sobre como uma base curricular pode contribuir para que os jovens alcancem seu projeto de vida, foi fundamental a parceria com a Plano CDE.

Evidências internacionais também têm sido levantadas, discutidas e disseminadas pelo Movimento. Por exemplo, as experiências de Colômbia, Chile, África do Sul e Coreia do Sul com o desenho e a implementação curricular, grandemente inspirada em Max Moder; ou ainda, se há tendências acerca de conteúdos em diversos currículos (Curriculum Foundation) e entendimento de como outros países organizam seu Ensino médio - Curriculum Foundation e Australian Curriculum Assessment and Reporting Authority (Acara).

Para além dessas e de outras pesquisas, o Movimento realizou encontros e seminários envolvendo especialistas nacionais e internacionais, em que buscou ampliar as discussões sobre as lições aprendidas com o desenho, a construção, o conteúdo e a implantação de padrões nacionais de aprendizagem em países como Austrália, Estados Unidos, Chile, Reino Unido, Cingapura, Finlândia e Canadá. Engajou, ainda, especialistas brasileiros, australianos, americanos e ingleses na análise das três versões da Base Nacional divulgadas pelo MEC. Todas essas evidências foram apresentadas e discutidas com os envolvidos no processo de elaboração da Base, de maneira que pudessem ser consideradas em seus processos de tomada de decisão.

Francisco Aparecido Cordão - Uma das críticas em relação ao debate sobre a BNCC é que o Brasil está se espelhando nas experiências mais inovadoras que estão sendo realizadas no mundo todo para propor uma Educação Básica voltada às demandas do século 21 , ao passo que a formação ainda ofertada em grande parte de nossos cursos de licenciatura está voltada para a preparação de um professor, na melhor das hipóteses, que atenda aos reclamos do século 20, quando não, de séculos anteriores. Como enfrentar este desafio referente ao sério descompasso ainda enfrentado pela educação nacional, fruto da desarticulação entre educação básica e educação superior? 
Alice Ribeiro - Ao explicitar o que cada aluno tem o direito de aprender, a Base oferece uma excelente oportunidade para o ajuste da formação, de maneira que ela contribua para que os professores aprendam as competências, habilidades e os conteúdos, bem como as formas de ensiná-los e técnicas de gestão da sala de aula. Evidências nacionais e internacionais mostram que essas formações serão mais exitosas quanto mais conseguirem concretizar para os professores o que é esperado que os alunos aprendam e as diferenças entres as atuais e as novas aprendizagens previstas. Para isso, é essencial que a formação se valha de materiais de caráter prático, como exemplos de planos de aula, mapas de aprendizagem, itens de avaliações e exercícios alinhados aos objetivos de aprendizagem.

No caso da formação inicial, atividades práticas supervisionadas em escolas poderão apoiar essa finalidade de concretização e aquisição de importantes habilidades didáticas e pedagógicas. Ajustes nas Diretrizes de Formação de Professores, no Exame Nacional de Desempenho de Estudantes (Enade), nos concursos para seleção de docentes, o controle de qualidade dos cursos oferecidos e a criação de certificação docente alinhada à base no término dos cursos de Pedagogia e Licenciatura podem ser indutores importantes da mudança na formação inicial.

Já as formações continuadas, além de contarem com os já mencionados exemplos concretos do que é esperado que os alunos aprendam, poderão apresentar melhores resultados se forem realizadas de maneira regular nas escolas, com metodologias claras e pauta focada no que os professores ensinarão, quais materiais terão para apoiar isso, as dificuldades que podem encontrar e reflexões coletivas sobre como evoluíram desde a última formação. 